\title{
Transformational Leadership Role on Work Performance under the COVID 19 Pandemic in Zimbabwe
}

Tonderai Mathende and Asif Mahbub Karim

To Link this Article: http://dx.doi.org/10.6007/IJARBSS/v12-i1/12053

DOI:10.6007/IJARBSS/v12-i1/12053

Received: 07 November 2021, Revised: 12 December 2021, Accepted: 27 December 2021

Published Online: 11 January 2022

In-Text Citation: (Mathende \& Karim, 2022)

To Cite this Article: Mathende, T., \& Karim, A. M. (2022). Transformational Leadership Role on Work Performance under the COVID 19 Pandemic in Zimbabwe. International Journal of Academic Research in Business and Social Sciences, 12(1), 338-352.

\section{Copyright: (c) 2022 The Author(s)}

Published by Human Resource Management Academic Research Society (www.hrmars.com)

This article is published under the Creative Commons Attribution (CC BY 4.0) license. Anyone may reproduce, distribute, translate and create derivative works of this article (for both commercial and non0-commercial purposes), subject to full attribution to the original publication and authors. The full terms of this license may be seen at: http://creativecommons.org/licences/by/4.0/legalcode

Vol. 12, No. 1, 2022, Pg. $338-352$

Full Terms \& Conditions of access and use can be found at http://hrmars.com/index.php/pages/detail/publication-ethics 


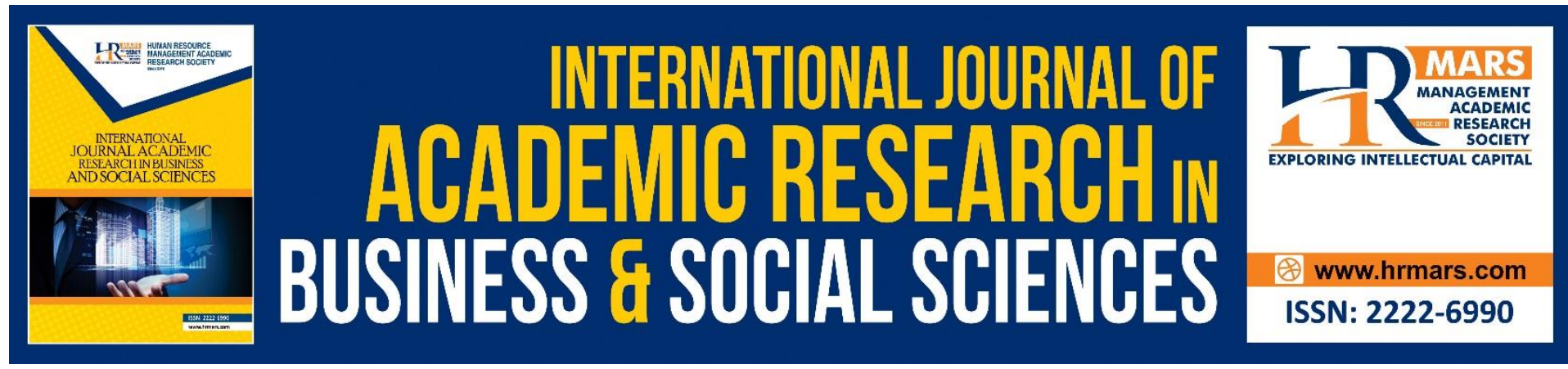

\title{
Transformational Leadership Role on Work Performance under the COVID 19 Pandemic in Zimbabwe
}

\author{
Dr. Tonderai Mathende ${ }^{1}$ and Dr. Asif Mahbub Karim ${ }^{2}$ \\ ${ }^{1}$ DBA Researcher, Binary University of Management \& Entrepreneurship, Malaysia and \\ ${ }^{2}$ Professor and Dean Binary University of Management \& Entrepreneurship, Malaysia
}

\begin{abstract}
COVID-19 outbreak has caused many changes in employees' routine and activities, as well as in managerial leadership styles in mitigating the COVID-19's implications. During the COVID 19 era, leadership practices have been criticized as insignificant. To a considerable degree, this is due to the reactive mode and mismatching solutions offered to the prevailing situation by leaders in trying to enhance employees' perceptions in their safety, welfare and work tools support. However, as transformational leadership is the most suitable leadership style to lead human resources in uncertain environments. The objective of this research is to examine transformational leadership role on work performance among Beverage's manufacturing companies who have been working during the pandemic. This is quantitative research which comprises of a sample of 369 employees who were selected using probability sampling where a self-administered survey questionnaire was administered on employees and the responses were analyzed using various statistical techniques. The results show that each dimension of transformational leadership predicts work performance, although not the same extent. This pandemic inevitably pushed for new leaderships skills that can become an integral part of the post-pandemic world. Hence the research provides important practical implications for improving employee's performance through appropriate leadership traits.
\end{abstract}

Keywords: Transformational Leadership, Work Performance, COVID-19 and Pandemic

\section{Introduction}

Leadership plays a significant role to work performance (Sulasmi et al., 2020). Research indicates that different leadership styles are generally predictive of work performance (Hassi, 2019). However, COVID-19 outbreak has caused many changes in employees' routines and activities, as well as changes in managerial leadership styles in mitigating the COVID-19's implications. During the COVID 19 era, the leadership practices have been criticized as insignificant. However, some researches have suggested that the influence of leadership may vary across the contexts of organizations, environments, cultures and situations (Yom and Gibbs, 2021). In addition, research suggests that Transformational leadership style positively impacts on employees' performance in challenging environments. This is so because it is the most suitable leadership style to manage and lead resources in challenging environments (LaRocca and Groves, 2021). Therefore, this study examined the role of transformational 
leadership dimensions on work performance in Beverages manufacturing companies that largely practice transformational leadership style and have been working during COVID 19 pandemic era. Specifically, this research aims to, first, determine the dimension(s) of transformational leadership that influences work performance of organizations operating in the COVID-19 pandemic, and second, to examine the relationship between transformational leadership dimensions and work performance in pandemic environment.

\section{Background}

The coronavirus disease 2019 (COVID-19) pandemic began in December 2019 in China and it rapidly spread to the entire world (Hossain et al., 2020; Sher, 2020). It was declared a pandemic by the World Health Organization (Spinelli and Pellino, 2020). During this uncertain time the world come to a halt being affected by the deadly outbreak of the COVID-19 and the business community found it difficult to keep their business afloat (Diab-Bahman and Al-Enzi, 2020). This then left the employee and employer with many unanswered questions, unsure of the expectations from both to and from the employer and uncertainty in general. In such cases, emotional stresses mount and there was also failure and fear to follow rushed or unexpected transition prevailing to mitigate the pandemic.

Now, this COVID -19 pandemic has emerged to be a good example of a complex business environment and came as an evaluation tool to assess about their preparedness to lead organizations in which to remain a going concern despite challenging environments (Nangia \& Mohsin, 2020). Furthermore, the coronavirus pandemic has helped to shed more light on what happens to organizations that lack appropriate agile leadership which respond slowly to threats. Before COVID-19 pandemic no business was immune to technological changes, globalization, political and economic challenges, but these changes did not affect business globally the same time. The effects slowly impacted the nations and gradually spread globally. In other words, it was at the pleasure of dictates of the trends in individual businesses. However, the impact of COVID 19 pandemic did not spread gradually globally, but its impact spread rapidly to the business community globally including the Zimbabwean organizations which this paper seeks to focus on. In that regard, appropriate leaders with appropriate leadership style are crucial whose vision can see through where the pandemic is taking the organizations to. Of which, the right kind of employees who are adaptable and who can quickly change direction when the need arises match this environment.

The context under which this study is carried out is pandemic driven complex environment. It is a pandemic because the disease spreads over multiple countries and continents negatively affecting humans, working environments and work performances. Work performance can be a measure of productivity of the organization, including quality of its products and quantity of products produced per unit time. These are achieved not only by aligning employees to the organization's strategy, but they are also achieved by providing a conducive environment which motivates employees to believe in the supporting environment and wanting to work in it. This suggest that, there are three dimensions that need to be considered by an organization to survive during pandemics and these are the leader, the employee and the context of the organization. The context of the organization in this research is COVID 19 situation which has posed serious threats to the business operations rendering this situation to be an unconducive working environment. However, leadership 
plays a significant role in creating a conducive environment to enhance work performance (Khaliq et al., 2021).

Research indicates that leadership styles influence employees differently under different environments and as such employees respond differently to different leadership styles (Alheet et al., 2021). However, transformational leadership style is the most suitable leadership style to practice under unprecedented environmental conditions (Buil et al., 2019). Despite several studies on leadership, including the contemporary transformational leadership studies which show that transformational leadership practices can positively transform employees and organizations, results obtained from previous researches are inconclusive and or contradictory. There is dearth of evidence on the relationship, application and practice of transformation leadership style on work performance under the pandemic contexts in Zimbabwe. This suggest that there is need for more researches on transformational leadership on work performance in organizations particularly under the COVID-19 pandemic. Ma \& Yang (2020) argued that the COVID-19 pandemic has exposed many organizational problems of leadership crisis and management ineptitudes. Again, it also exposes general insufficient research on leadership style on work performance under pandemic situations.

\section{Literature Review}

Literature substantiates that among several leadership styles, transformational leadership style is widely used in organizations and it plays a significant role on organizational performance (Arif and Akram, 2018). Several studies done on transformational leadership have examined how this leadership style impacts on employee performance based on the premises that employee performance always improves organizational performance (Li et al., 2019). However, in a pandemic complex situation, employee performance with poor leadership may fail to enhance organizational performance (Manzoor et al., 2019). In that regard, more research is required to understand how leadership contributes to employee performance in hostile environments which leaders themselves have little control over. Nonetheless, there is lack of robust research on Transformational leadership style under the pandemic situation and this situation has become the new normal in Zimbabwe which has inevitably pushed for new leaderships skills that can potentially become an integral part of the post-pandemic world.

\section{Transformational Leadership and Work Performance}

Literature substantiates that each dimension of transformational leadership influences work performance in unique ways in terms of how employees are motivated and inspired to willingly want to exceed their expectations. These dimensions of transformational leadership are; first, Idealized Influence which refers to the charismatic characteristics of the leader who behaves as a role model for others where the employees admire, respect and trust the leader (Hutagalung et al., 2021). Ultimately, followers identify with their leader's goals, interests and values. Second, intellectual stimulation is the leader's ability to help followers to think on their own, through challenging them by questioning and developing their beliefs, assumptions and values then followers are motivated to be creative and innovative in solving problems (Magasi, 2021) Third, Inspirational Motivation entails the ability of a leader to promote followers' emotional commitment and excitement to a mission by not only providing challenging tasks and promoting positive expectations of what needs to be done, but also, 
demonstrating commitment to the shared vision (Muppidathi and Krishnan, 2021). Last, Individualized Consideration, whereby the leader assists followers to become fully actualized by providing personalized career guidance (Alshamsi et al., 2020).

However, the extent of the influence of each dimension of transformational leadership on work performance is varied and at times conflict each other (Lai et al., 2020). This suggests that, in unprecedented environments such as the COVID-19 situation, to continue viewing transformational leadership as a composite or single construct may not bring out the deeper understanding and conclusive results which can be generalized in different challenging environments. Instead, transformational leadership is understood more when it is broken down to factors which are then studied as separate dimensions. However, few attempts that attempted to study transformational leadership dimensions separately yielded conflicting results. This may be partly due to different environmental contexts under which these studies were conducted. In light of the COVID-19 outbreak which has caused social isolation, anxiety, fear of contagion and uncertainty among employees, organizations came to a halt. Therefore, the study of the role of specific dimensions of transformational leadership becomes crucial because specific leadership traits are the only source of hope for the employees to increase their work engagement and consequently work performance. Manzoor et al (2019) argue that organizations that seek to remain competitive are those that are focused at improving employees work performance. While work performance is enhanced by transformational leadership approach, transformational leadership deals with change processes which in turn transforms followers' attitudes, belief and values (Pasha and Ur Rehman, 2020). Therefore, this paper aims to determine the transformational leadership dimension(s) which influences work performance in a pandemic situation.

Transformational leaders are obliged to create and provide their employees with a conducive organizational climate to enable employees to successfully carry out their work (Imran et al., 2012). The conducive organizational climate includes but not limited to shared perceptions of the values, policies, missions, ethics and morals which are formulated and implemented by leaders as wells a protective equipment and clothing (Garg et al., 2017). According to Monika and Kaliyamurthy (2017), support rendered by leaders removes fear and uncertainty, and it creates feelings that potentially influence employees' behaviors and attitudes to energize them to work hard. Therefore, this research also aims to examine whether each dimension of transformational leadership positively predict work performance in a COVID 19 pandemic situation.

\section{The Conceptual Framework}

The relationship between each transformational leadership dimension and work performance are illustrated in the conceptual frame. The dimensions of transformational leadership positively impact on employee work performance. The important issues underpinning this conceptual framework is to stress the role of five transformational leadership dimensions in improving work performance in the wake of the pandemic. The diagram shows five independent variable namely inspirational motivation, idealized influence attributed, idealized influence behavioral, intellectual stimulation and individualized consideration. The diagrammatic presentation further presents one dependent variable which is work performance. 


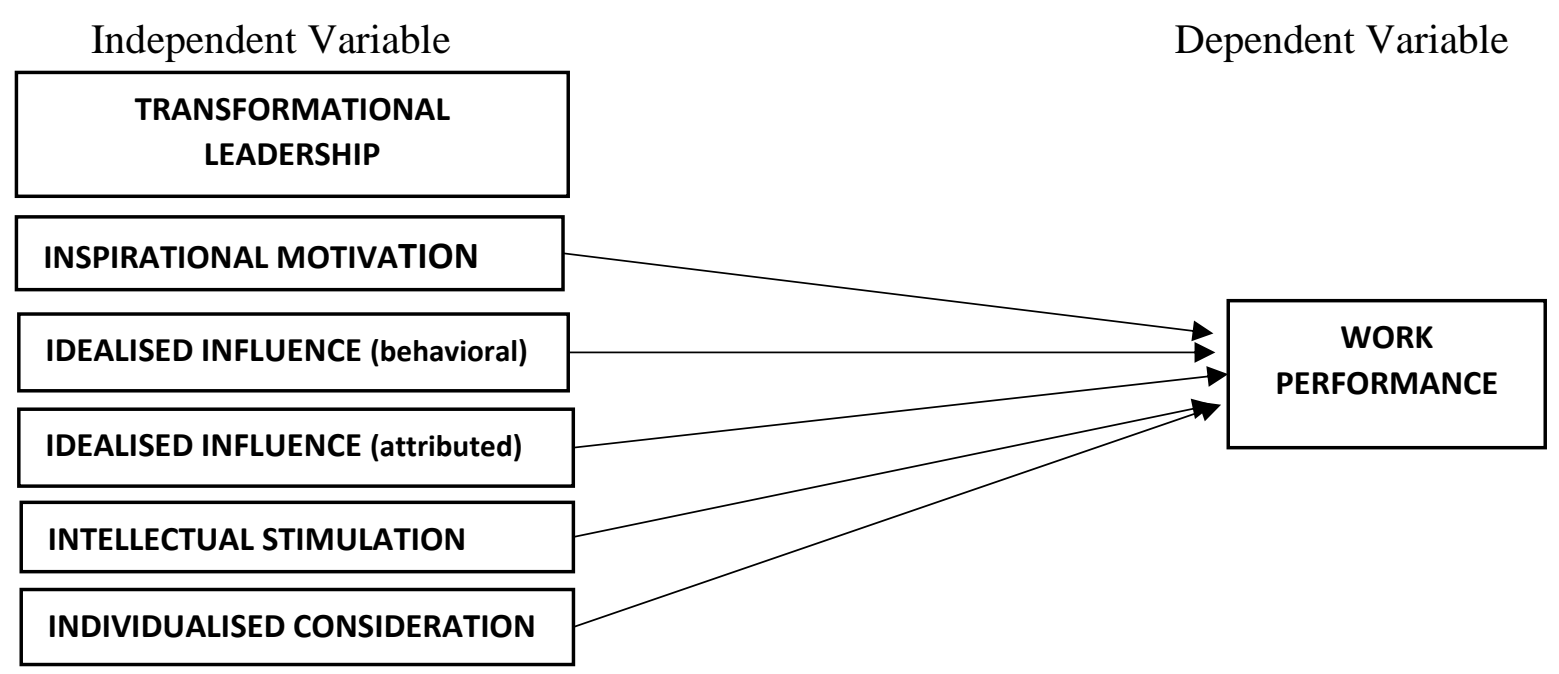

Fig 1 Conceptual framework

\section{Research Methodology}

A total of 369 participants were selected using systematic random sampling techniques. A survey questionnaire was used for data collection and data were analyzed using descriptive and inferential statistics. Pearson's correlation was used ahead of other techniques like spearman's rho correlation because although the data has ranked variables (ordinal data) which makes it a non-parametric statistic, this study conducted normality tests which revealed an approximately normally distributed data. The study used one-way ANOVA and post hoc comparisons of mean values using Tukey HSD in order to identify the extent to which dimensions of transformational leadership style influence work performance of organizations operating in the COVID 19 pandemic situation. Therefore, work performance was the dependent variable while the dimensions of transformational leadership were the independent variables. One-way ANOVA was the most appropriate in this study because it is a robust method for evaluating differences between groups and the post hoc test of ANOVA is advantageous in that it can control the type 1 error (Jorgensen et al., 2018) than a similar t-test analysis technique. In this this study, a p-value of less than 0.05 was required for significance. Further, simple linear regression using SPSS was used to explore the predictive abilities of transformational leadership dimensions on work performance because it provides a more detailed analysis to predicting, optimizing, or explaining a numeric response of work performance from transformational leadership, since other predictive statistical tools like correlation provides a quick and simple summary of the direction and strength of pairwise relationships between variables. But this study seeks to predict and explain relationships.

\section{Sample and Sampling Techniques}

The sample consisted of all employees of the organizations who were systematically randomly selected to participate in the study. The procedure was that, after every ninth person on the lists, all the tenth persons were recorded as the potential participants which gave rise to the target population of approximately 7000 employees. Then, 700 questionnaires were sent to participants through a blind cope email and through hard copies to those not on email and a sample size of 364 was adequate (Krejcie and Morgan 1970). However, 369 questionnaires were returned and usable denoting a rate of return of $52 \%$. The results were quantified using 
SPSS software package. The survey questionnaire used a descriptive rating on a Likert-scaletype on well-structured questions adapted from previous studies.

\section{Data Collection and Analysis}

The survey instruments included the Multifactor Leadership questionnaire (MLQ) and Work performance questionnaire. These questionnaires were combined into one continuous document and were made available for participants to access on their computers, or on their personal devices. The independent variables were the 5'I's of transformational leadership. The questions on transformational leadership dimensions comprises of twenty items adopted from the MLQ which were rated on a 5-point Likert scale from 1 to 5 , that is $1=$ strongly disagree to 5 = strongly agree. Additionally, each dimension on the MLQ survey has four statements and each statement started with the phrase, "The person I am rating..." then followed by phrases such as, goes beyond self-interest; models ethical standards; emphasizes the collective mission; talks optimistically; arouses awareness about important issues. Then the questions for work performance were adapted from the work of Koopmans et al., (2013, 2014) and consist of a Likert-type scale that has eight questions and the answer options range from 1 to 5 , to say 1 = strongly disagree and $5=$ strongly agree. For example, the questions read; my quality of work is higher than average, my work load is higher than average level of the department, I always complete my task on time.

\section{Results}

\section{Normality Test}

The results of Normality test using Shapiro-Wilks test $(p>0.05)$ shows that work performance is approximately normally distributed for all transformational leadership dimensions (Table 4.1), which means that the sample data were drawn from normally distributed population. Therefore, the sample means, and standard deviations are representatives of the data, and ANOVA and regression analysis are applicable for this study.

Table 1 Shapiro-Wilks Test

\begin{tabular}{|c|c|c|c|c|}
\hline & \multicolumn{3}{|c|}{ Shapiro-Wilks Test } \\
\hline & & Statistic & $\mathrm{df}$ & Sig. \\
\hline \multirow{5}{*}{$\begin{array}{l}\text { Work } \\
\text { Performance }\end{array}$} & Inspirational Motivation & 0.967 & 40 & 0.722 \\
\hline & Idealized influence (A) & 0.954 & 42 & 0.087 \\
\hline & Idealized Influence (B) & 0.946 & 42 & 0.088 \\
\hline & Intellectual stimulation & 0.954 & 43 & 0.086 \\
\hline & Individualized consideration & 0.978 & 39 & 0.623 \\
\hline
\end{tabular}

\section{Pearson's Correlation of Constructs}

Table 4.2 below shows correlation among variables with a confidence interval of $95 \%$ and a statistical significance of $p<0.05$, 
Table 2 Pearson's correlations of the constructs

\begin{tabular}{lllllll}
\hline & IM & IFB & IFA & IS & IC & WP \\
\hline Inspirational_motivation (IM) & 1.000 & & & & & \\
Idealised_influence_behavioral (IFB) & .751 & 1.000 & & & & \\
Idealised_influence_attributed (IFA) & .663 & .680 & 1.000 & & & \\
Intellectual_Stimulation (IS) & .726 & .680 & .546 & 1.000 & & \\
Indivualised_Consideration (IC) & .603 & .641 & .527 & .647 & 1.000 & \\
Work_Perfomance (WP) & .525 & .461 & .480 & .499 & .402 & 1.000 \\
\hline
\end{tabular}

Results for the Influence of TL dimensions on work performance Descriptive Statistics

Table 3 below shows descriptive statistics; the mean values, standard deviations, standard error, confidence interval for the mean, as well as the one-way ANOVA in Table 4.4. The descriptive statistics results were read in conjunction with ANOVA and post hoc test results to describe the effect of each transformational leadership dimension on work performance.

Table 3 Results of the Descriptive statistics and one-way ANOVA

\begin{tabular}{|c|c|c|c|c|c|c|c|}
\hline & \multirow[b]{2}{*}{ Mean } & \multirow[b]{2}{*}{ SD } & \multirow[b]{2}{*}{ SE } & \multicolumn{2}{|c|}{$95 \% \mathrm{Cl}$ for Mean } & \multirow[b]{2}{*}{ Min } & \multirow[b]{2}{*}{ Max } \\
\hline & & & & Lower & Upper & & \\
\hline Idealized influence (A) & 16.78 & 2.57 & 0.157 & 14.367 & 19.193 & 4.00 & 20.00 \\
\hline Idealized influence (B) & 16.84 & 2.50 & 0.145 & 14.485 & 19.195 & 4.00 & 20.00 \\
\hline $\begin{array}{l}\text { Inspirational } \\
\text { Motivation }\end{array}$ & 17.12 & 2.49 & 0.147 & 14.777 & 19.463 & 4.00 & 20.00 \\
\hline Intellectual Stimulation & 16.44 & 2.57 & 0.159 & 14.029 & 18.851 & 4.00 & 20.00 \\
\hline $\begin{array}{l}\text { Individualized } \\
\text { Consideration }\end{array}$ & 16.33 & 2.39 & 0.142 & 14.082 & 18.578 & 4.00 & 20.00 \\
\hline
\end{tabular}

Table 4 One-way ANOVA

\begin{tabular}{llllll}
\hline Source & SS & df & MS & F & Sig \\
\hline Between & 152.221 & 4 & 38.055 & 6.076 & .000 \\
Within & 2029.216 & 364 & 6.263 & & \\
Total & 2181.437 & 368 & & & \\
\hline
\end{tabular}

The one-way ANOVA indicates that the overall test of the descriptive was significant, $F(4$, $364)=6.076, p=0.001$

\section{Multiple Comparisons of the Mean Values}

Further, a post hoc comparison using the Tukey HSD test to compare the means of the five dimensions of transformational leadership was also done and the Multiple comparisons of the mean values shows that

the mean score for Inspirational motivation ( $M=17.12$, $S D=2.49$ ) was statistically significantly different than the other four practices, that is, Idealized influence-behavioral, (M $=16.84, \mathrm{SD}=2.50, \mathrm{p}=0.009)$; Idealized influence-attributed $(\mathrm{M}=16.78, \mathrm{SD} 2.57, \mathrm{p}=0.002$; Intellectual stimulation ( $\mathrm{M}=16.44, \mathrm{SD}=2.57, \mathrm{p}=0.001$ ) and Individualized consideration ( $\mathrm{M}$ $=16.33, \mathrm{SD}=2.39, \mathrm{p}=0.001$ ). On another note, Idealized influence (behavioral) is statistically significant than intellectual stimulation and individualized consideration with the same $p$ - 
value of 0.001 . Similarly, Idealized influence (attributed) is statistically significant than intellectual stimulation and individualized consideration with the $p$-values of 0.017 and 0.003 respectively. However, idealized influence-behavioral $(M=16.84, S D=2.50)$, did not statistically significantly differ from idealized influence-attributed $(M=16.78, S D=2.57), p-$ value $=0.369$. Similarly, intellectual stimulation $(M=16.44, S D=2.57)$, did not statistically significantly differ from individualized consideration $(M=16.33, S D=2.39)$, $p$-value $=0.545$.

Overall, there is a statistical significance between the mean values of the group under study, $F(4,364)=6.076, p=0.001$. In that regard, the most influential dimension of transformational leadership on work performance is Inspirational motivation followed by idealized influence, followed by intellectual consideration and the least rated is individualized consideration. Further, the statistical relationships between each dimension of transformational leadership and work performance were all significant.

\section{Results for the Regression analysis}

Table 5 Regression equation coefficients for Five Dimensions of TL with Work performance

\begin{tabular}{llllllll}
\hline Variables & $\mathrm{R}^{2}$ & $\mathrm{~F}$ & $\mathrm{~B}$ & $\mathrm{SE}$ & $\beta$ & $\mathrm{t}$ & $\mathrm{Sig}$. \\
\hline Constant & & & 14.064 & 1.190 & & 11.814 & .000 \\
Inspirational Motivation & 0.43 & 253.91 & 1.097 & 0.069 & 0.66 & 15.935 & .000 \\
& 7 & & & & 1 & & \\
\hline $\begin{array}{l}\text { Constant } \\
\text { Idealized influence }\end{array}$ & 0.477 & 298.55 & 1.145 & 0.066 & 0.691 & 17.28 & .000 \\
(behavior) & & 5 & & & & & \\
\hline $\begin{array}{l}\text { Constant } \\
\text { Idealized influence }\end{array}$ & 0.458 & 276.17 & 1.088 & 0.065 & 0.67 & 16.618 & .000 \\
(attributed) & & 4 & & & 7 & & \\
\hline $\begin{array}{l}\text { Constant } \\
\text { Intellectual Stimulation }\end{array}$ & 0.506 & 334.92 & 1.145 & 0.063 & 0.71 & 18.301 & .000 \\
& & & & & 1 & & \\
\hline Constant & & & 14.804 & 1.221 & & 12.12 & .000 \\
& & & & & & 8 & \\
Individualized & 0.405 & 222.8 & 1.104 & 0.074 & 0.63 & 14.92 & .000 \\
Consideration & & 5 & & & 7 & 8 & \\
\hline
\end{tabular}

Table 5 above indicates a significant regression analysis on all the dimensions of transformational leadership and work performance. That is, Inspirational motivation recorded $F(1,367)=253.91$, $p$-value $=0.001$ with $R^{2}=0.437$ explains a variance of $43.7 \%$ and Beta value of 0.661 denoting a significant relationship that Inspirational motivation predicts work performance. Then, Idealized influence (behavioral) recorded $F(1,367)=298.555, p$ value $=0.001$ with $R^{2}=0.477$ explains a variance of $47.7 \%$, and Beta value of 0.691 denoting a significant relationship that Idealized influence behavioral predicts work performance. Then, Idealized influence (attributed) recorded $F(1,367)=276.174, p$-value $=0.001$ with $R^{2}=$ 0.458 explains a variance of $45.8 \%$, and Beta value of 0.667 denoting a significant relationship that idealized influence attributed predicts work performance. Then, Intellectual stimulation recorded $F(1,367)=334.92$, $p$-value $=0.001$ with $R^{2}=0.506$ explains $50.6 \%$ variance and Beta value of 0.711 denoting a significant relation that intellectual stimulation predicts work performance. Finally, Individualized consideration recorded $F(1,367)=222.85, p$-value $=$ 
0.001 with $R^{2}=0.405$ explains $50.6 \%$ variance, and Beta value of 0.637 denoting a significant relationship that individualized consideration predicts work performance.

\section{Discussion}

The study provided an exhaustive analysis of the results and findings. The findings and analysis in this research were mainly consistent with literature related to transformational leadership and work performance. The study clearly confirms the importance of transformational leadership style for organization operating in unprecedented environments. In which the interaction of the five dimensions of transformational leadership on work performance revealed significant relationships. These relationships are such that transformational leadership dimensions have direct effects on work performance. Since the study was performed for organizations operating in the pandemic era, the findings of this study provided additional evidence on the relationship between transformational leadership dimensions and work performance under challenging environment.

This research paper shows that although transformational leadership dimensions jointly influence work performance, the degree of influence differs particularly in COVID-19 pandemic environments. As such, in this pandemic situation, inspirational motivation is ranked the most influential dimension, followed by idealized influence (behavioral and attributed). Then the third influential dimension is intellectual stimulation and the least influential dimension is individualized consideration. This finding supports objective of this research which was to identify the dimension(s) of transformational leadership that influences work performance during pandemic situations. Similarly, Vu, Vu and Hoang (2020), also found out that all the five dimensions of transformation leadership are predictors of work performance, but on the contrary, Idealized influence - attributed was ranked the most influential dimension. Previously, Aslan, (2019) revealed that idealized influence -behavior impact the most on work performance. Further, Chan et al (2019) revealed otherwise that, Inspirational motivation was ranked the least among transformational leadership dimensions in influencing work outcome. These contradictory results may give an indication that work performances under different environments are affected the most by certain transformational leadership characteristics. However, the findings of this research revealed that pandemic situations require the inspirational motivation the most.

The findings of this study imply that during the pandemic situations, leaders achieve organizational performance by providing guidance and assurance through talking to employees enthusiastically and optimistically while at the same time arousing their awareness about the importance of containing the pandemic as well as following the health guidelines, restrictions, rules and regulations. This gives employees hope and trust in their leaders and it evokes sense of excitement and assurance that the direction the organization is taking is the right direction and that the organization cares for their wellbeing. This is in line with Arokiasamy and Tat (2020) who attests that well-articulated vision supported by skillful communication makes the vison clear, powerful and engaging such that employees are aroused to believe in their abilities despite the challenges and they to successfully complete their tasks. This removes the panic brought about by pandemic situations and it encourages team cohesion and stops team integration. 
Although idealized influence behavioral and idealized influence attributed were ranked the second and third respectively, they do not statistically significantly differ. This suggests that both attributed and behavioral idealized influences can be treated as one construct and this is in line with the attestations of Erden and Yaşlioğlu (2020) who referred to both attributed idealized influence and behavioral idealized influence as simply a charismatic behavior of a leader. Now, this characteristic is associated with walking the talk and acting consistently in building the commitment towards the vision. In the pandemic situation, the leader achieves this by exhibiting high ethical or moral standards and sense of purpose while taking the dangers of pandemic into consideration and putting peoples first. In turn, employees respect and view the manager as their role model. However, the difference in the ranking of these dimensions can be credited to the fact that that idealized influence behavior has strong influential personal behaviors that demonstrates values, belief and sense of mission, whereas the idealized influence attributed possesses strong influential traits that encourages employees to think highly about their superiors. Therefore, in pandemic situations the behaviors of managers appeal more to employees than it does on their traits. This is in line with the research by Baba (2019), which showed that idealized influence (behavioral) is the most practiced and influential transformational leadership factor among leaders in the academic set up. Therefore, during pandemic environments, employees are motivated and inspired more by what managers do as oppose to what managers are. What "managers do" may include considering and modelling moral and ethical standards, talking of values and always emphasizing the need for collective mission and team work, contrary to "what managers are" where the emphasis may be on power and authority, altruism and confidence. However, the findings revealed that, employees emulate and want to do and identity with managers who live their principles.

Intellectual stimulation is ranked the fourth in terms of influencing work performance, but the influence is still significant. The finding of this present study is similar to the finding of the previous study by Nguyen et al (2019) which show that, intellectual stimulation creates the ability in employees to analyze and deduce issues which in turn provoke proactive feeling in them to make effective plans to implement and exceedingly meet optimistic goals, which in turn, increases work performance. This implies that in challenging environments, managers ought to be highly knowledgeable in every aspect of the business. In fact, during periods of pandemics, employees may be craving for different views and angles from their managers on how to deal with the uncertainty affecting their places of work. In that case, the ranking of Intellectual stimulation on the fourth position, though significant, may indicate that the rapid environmental changes characterized by strict restrictions and lockdowns may at times overtake the most needed managerial intellectual interventions that include guidance and assurance in the execution of their tasks. Before employees fully realize the importance of the guidance provided it would have been overtaken by the new effects on a new variant. However, intellectually stimulated employees are likely to view problems created by pandemic situations as an opportunity for them to learn and show what they can do at all cost to resolve the problem. In that regard pandemic driven complex situations may be a platform to showcase their capabilities because intellectual stimulation is associated with creativity and innovation. This is in line with the study by Muchiri et al (2020), which affirm that innovative work behaviors stimulate idea generation and implementation. 
The least rated transformational leadership practice is individualized consideration, but the results also show that the relationship is significant. The results of this study are in line with the results of the research by Munyeki and Were (2019) which shows that individualized consideration has positive and significant effect on performance. However, the ranking of individualized consideration is contrary to the study by Baba (2019) whose results show that individualized consideration is the second most influential transformational leadership factor after Idealized influence-behavioral. However, the numerically low ranking of the perception by respondents is accredited to low attention to individual needs that manager provide to employees during the pandemic situations. In which case the pace at which the pandemic rolls out may out-pace the initiatives of managers to focus on the individual awareness, training and development. The contributing factor is that before employees realize their next full level of self-belief and self-actualization they would have been overtaken by the fastchanging events of the pandemic. In which case, may fail to cope up fully with the trends and effect of the variants of COVID 19 pandemic and its variants. Specifically, managers are involved in identifying and satisfying individual needs, retraining and coaching employees to match their skills and capabilities with the then new order created by the variants of COVID 19. This implies that individualized attention is very important in providing individualized guidance, advice, great care, work tools and concern for the employees in the pandemic times.

\section{Conclusion}

While the outbreak of COVID19 has caused several operational challenges, transformational leadership can help cope with the current challenges and post the pandemic period. The dimensions of Transformational leadership impact on work performance in unique and different ways and it brought deeper and sharper distinct understanding of their contributions in relation to work performance in the pandemic environment with effective communication, dealing with uncertainty and ambiguity, provision of guidance, support, safety and welfare of employees. Present study contributes evidence of the uniqueness of each dimension of leadership to influencing work performance. This paper also closes the contextual and literature gap on transformational leadership and work performance in which transformational leadership validated the importance of its dimensions in influencing outcomes despite pandemics. This study provides several implications to management practices and offer managers a comprehensive framework by which to understand what contributes to high employee work performance in pandemic situations like the COVID 19 environments. Therefore, by keeping in view of the current results, this paper considers transformational leadership as highly capable of dealing with uncertain environments for work performance for now and into the post-pandemic world.

One of the research limitations is that the research used quantitative research design. Moreover, there mixed method that can be used to draw other insights. In addition, examining the role of transformational leadership in Beverages organizations further narrows down the current research. However, clarity was provided, and this paper recommends more studies on the leadership during emergencies.

\section{References}

Alheet, A., Adwan, A., Areiqat, A., Zamil, A., \& Saleh, M. (2021). The effect of leadership styles on employees' innovative work behavior. Management Science Letters, 11(1), 239-246. 
Arif, S., \& Akram, A. (2018). Transformational leadership and organizational performance: the mediating role of organizational innovation. SEISENSE Journal of Management, 1(3), 5975.

Arokiasamy, A., \& Tat, H. (2020). Exploring the influence of transformational leadership on work engagement and workplace spirituality of academic employees in the private higher education institutions in Malaysia. Management Science Letters, 10(4), 855-864.

Aslan, H. (2019). The Mediating Role of Leader-Member Exchange in The Effect of Transformational Leadership on Employee Performance and Job Satisfaction. Business and Economics Researches Book, 201-214.

Baba, M. M. (2019). Transformational Approach to Higher Educational Leadership, International Journal on Leadership. Vol. 7(1), pp. 22-34.

Buil, I., Martínez, E., \& Matute, J. (2019). Transformational leadership and employee performance: The role of identification, engagement and proactive personality. International Journal of Hospitality Management, 77, 64-75.

Chan, S. W., Ang, S. F., Andleeb, N., Ahmad, M. F., \& Zaman, I. (2019). The influence of transformational leadership on organization innovation in Malaysian manufacturing industry. International Journal of Supply Chain Management, 8(2), 971-976.

Choudhary, N., Kumar, R., \& Philip, P. J. (2016). Effects of transformational leadership on follower's organizational citizenship behavior: The moderating role of culture. Prabandhan: Indian Journal of Management, 9(7), 23-33.

Diab-Bahman, R., \& Al-Enzi, A. (2020). The impact of COVID-19 pandemic on conventional work settings. International Journal of Sociology and Social Policy.

Eden, D., Ganzach, Y., Flumin-Granat, R., \& Zigman, T. (2010). Augmenting means efficacy to boost performance: Two field experiments. Journal of Management, 36(3), 687-713.

Figueiredo, P., \& Sousa, M. J. (2016). Leaders and Followers: The Leadership Style Perceived in Modern Organizations. In Handbook of Research on Information Architecture and Management in Modern Organizations (pp. 195-218). IGI Global.

Garg, V., Singh, V. P., \& Raj, V. (2017). Development of Water Resources in India. Basingstoke, England, Springer.

Hassi, A. (2019). Empowering leadership and management innovation in the hospitality industry context: The mediating role of climate for creativity. International Journal of Contemporary Hospitality Management.

Hossain, M. I., Polas , M. R. H., Rahman, M. M., Islam, T., \& Jamadar, Y. (2020). An Exploration of COVID-19 Pandemic and its Consequences on FMCG Industry in Bangladesh. Journal of Management Info, 7(3), 145-155. https://doi.org/10.31580/jmi.v7i3.1484

Imran, R., Fatima, A., Zaheer, A., Yousaf, I., \& Batool, I. (2012). How to boost employee performance: investigating the influence of transformational leadership and work environment in a Pakistani perspective. Middle-East Journal of Scientific Research, 11(10), 1455-1462.

Jorgensen, T. D., Kite, B. A., Chen, P. Y., \& Short, S. D. (2018). Permutation randomization methods for testing measurement equivalence and detecting differential item functioning in multiple-group confirmatory factor analysis. Psychological methods, 23(4), 708.

Khalifa, G. S., Binnawas, M. S., Alareefi, N. A., Alkathiri, M. S., Alsaadi, T. A., Alneadi, K. M., \& Alkhateri, A. (2021). The Role of Holistic Approach Service Quality on Student's Behavioural Intentions: The Mediating Role of Happiness and Satisfaction'. City University eJournal of Academic Research (CUeJAR), 3(1), 12-32. 
Khaliq, M., Usman, A., \& Ahmed, A. (2021). Effect of Leadership Style on Working Culture and Employees Motivation. The Journal of Educational Paradigms, 3(1), 166-170.

Koopmans, L., Bernaards, C., Hildebrandt, V., Van Buuren, S., Van der Beek, A. J., \& de Vet, H. C. (2013). Development of an individual work performance questionnaire. International journal of productivity and performance management.

Krejcie, R. V., \& Morgan, D. W. (1970). Determining sample size for research activities. Educational and psychological measurement, 30(3), 607-610.

Lai, F. Y., Tang, H. C., Lu, S. C., Lee, Y. C., \& Lin, C. C. (2020). Transformational leadership and job performance: the mediating role of work engagement. SAGE Open, 10(1), 2158244019899085.

LaRocca, M. A., and Groves, K. S. (2021). Transformational Leadership in Extreme Contexts: Associations with Posttraumatic Growth and Self-Efficacy Among Combat Veterans. Armed Forces \& Society,

Li, H., Sajjad, N., Wang, Q., Muhammad Ali, A., Khaqan, Z., \& Amina, S. (2019). Influence of transformational leadership on employees' innovative work behavior in sustainable organizations: Test of mediation and moderation processes. Sustainability, 11(6), 1594.

Ma, M. H., \& Yang, Q. S. (2020). How does transformational leadership work on COVID-19? An empirical evidence from China. Journal of Innovative Studies, 1(2).

Magasi, C. (2021). Moderating Effect of Individualised Consideration on the Relationship between Intellectual Stimulation and the Performance of Banking Sector Employees.

Manzoor, F., Wei, L., Nurunnabi, M., Subhan, Q. A., Shah, S. I. A., \& Fallatah, S. (2019). The impact of transformational leadership on job performance and CSR as mediator in SMEs. Sustainability, 11(2), 436.

Mashavira, N. (2016). Performance management in family and nonfamily owned SMEs in Zimbabwe and South Africa, Interim, Interdisciplinary Journal, 15 (2), 32-52.

Monika, M., \& Kaliyamurthy, K. (2017). Effect of Organizational Climate in Job Satisfaction among the Employees. Asian Journal of Research in Social Sciences and Humanities, 7(8), 217-227.

Muchiri, M. K., McMurray, A. J., Nkhoma, M., \& Pham, H. C. (2020). Mapping antecedents of innovative work behavior: A conceptual review. The Journal of Developing Areas, 54(4).

Munyeki, N., \& Were, S. (2017). Influence of transformational leadership on the performance of project based organizations: A case of International Livestock Research Institute. International Journal of Project Management, 1(3), 41-60.

Nangia, M., \& Mohsin, F. (2020). Identifying VUCA factors in a pandemic era-a frame-work focused on Indian IT industry. Journal of Critical Reviews, 7(7), 931-936.

Ngaithe, L. N., K'Aol, G. O., Lewa, P., \& Ndwiga, M. (2016). Effect of idealized influence and inspirational motivation on staff performance in state owned enterprises in Kenya, European Journal of Business and Management, 8(30), 6-13.

Nguyen, H. M., Mai, L. T., \& Huynh, T. L. (2019). The role of transformational leadership toward work performance through intrinsic motivation: A study in the pharmaceutical field in vietnam. The Journal of Asian Finance, Economics, and Business, 6(4), 201-212.

Pasha, M. A., \& Ur Rehman, M. Z. (2020). Impact of transformational leadership and psychological empowerment on meaningful work, moderating effect of organizational culture. Abasyn University Journal of Social Sciences, 13(1).

Renjith, V., Renu, G., and George, A. (2015). Transformational leadership in Nursing', International Journal of Science Research and management studies, 2(2), 112-118 
Sher, L. (2020). The impact of the COVID-19 pandemic on suicide rates. QJM: An International Journal of Medicine, 113(10), 707-712.

Spinelli, A., \& Pellino, G. (2020). COVID-19 pandemic: perspectives on an unfolding crisis. Journal of British Surgery, 107(7), 785-787.

Sulasmi, E., \& Tanjung, H. (2020). Bridging The Way Towards Sustainability Performance Through Safety, Empowerment and Learning: Using Sustainable Leadership as Driving Force. Journal of Security \& Sustainability Issues, 10.

$\mathrm{Vu}, \mathrm{T} ., \mathrm{Vu}, \mathrm{M} ., \mathrm{\&}$ Hoang, V. (2020). The impact of transformational leadership on promoting academic research in higher educational system in Vietnam. Management Science Letters, 10(3), 585-592.

Yom, S. S., \& Gibbs, I. C. (2021). Leadership Versus Service: What's the Difference? Is There a Difference?. In Career Development in Academic Radiation Oncology (pp. 297-309). Springer, Cham. 